\title{
Criatividade em Sala de Aula: Fatores Inibidores e Facilitadores Segundo Coordenadores Pedagógicos
}

\author{
Eunice Soriano de Alencar ${ }^{1}$ \\ Denise de Souza Fleith ${ }^{1}$ \\ Clarissa Nogueira Borges ${ }^{2}$ \\ Evely Boruchovitch ${ }^{3}$ \\ ${ }^{1}$ Instituto de Psicologia da Universidade de Brasília, Brasilia, DF \\ ${ }^{2}$ Secretaria de Educação do Distrito Federal, Brasilia, DF \\ ${ }^{3}$ Departamento de Psicologia Educacional da Faculdade de Educaşão da Universidade Estadual de Campinas - UNICAMP, Campinas, SP
}

\begin{abstract}
Resumo
Este estudo investigou, em uma amostra de 66 coordenadores pedagógicos de instituições de ensino fundamental, fatores que dificultam o professor a estimular o desenvolvimento da criatividade discente e procedimentos que o coordenador poderia utilizar para apoiar o docente na promoção da criatividade em sala de aula. Os participantes responderam um questionário composto por uma checklist de barreiras à criatividade em sala de aula e quatro questões abertas. Desconhecimento pelo professor de práticas pedagógicas para favorecer o desenvolvimento da criatividade discente e de textos a esse respeito, além de insegurança para testar novas práticas pedagógicas foram os fatores inibidores mais sinalizados. Oferecer cursos para professores, além de orientação, apoio e incentivo aos docentes foram os procedimentos mais apontados pelos coordenadores para auxiliar o professor a encorajar a criatividade em sala de aula.

Palavras-chave: criatividade, coordenador pedagógico, escola, práticas docentes, professor
\end{abstract}

Creativity in the Classroom: Inhibiting and Facilitating Factors According to Pedagogical Coordinators

\begin{abstract}
This study investigated, in a sample of 66 elementary school pedagogical coordinators, factors that hamper teachers to stimulate the development of student creativity and strategies to be used by the coordinator to support teachers in promoting creativity in the classroom. Participants completed a questionnaire consisting of a checklist of obstacles to creativity in the classroom and four open questions. The most indicated inhibitory factors included the lack of knowledge by the teachers of pedagogical practices that favor the development of students' creativity and of texts in this respect, as well as insecurity to test new pedagogical practices. Providing courses, guidance, support and incentive for teachers were the procedures most frequently pointed out by coordinators to assist the teacher in encouraging creativity in the classroom.

Keywords: creativity; pedagogical coordinator; school; pedagogical practices; teacher
\end{abstract}

Creatividad en la Aula: Factores Inhibidores y Facilitadores Segundo Coordinadores Pedagógicos

\begin{abstract}
Resumen
Este estudio investigó, en una muestra de 66 coordinadores pedagógicos de instituciones de Enseñanza Primaria, factores que dificultan al maestro la estimulación del desarrollo de la creatividad del estudiante y también procedimientos que el coordinador podría utilizar para apoyar al profesor para promover la creatividad en clase. Los participantes respondieron un cuestionario compuesto por una lista de barreras a la creatividad en clase y cuatro preguntas abiertas. Desconocimiento por el profesor de prácticas pedagógicas para favorecer el desarrollo de la creatividad y de textos en este sentido, además de inseguridad para experimentar nuevas prácticas pedagógicas fueron los factores inhibidores más marcantes. Ofrecer cursos para maestros, así como orientación, apoyo e incentivo fueron los procedimientos más señalados por los coordinadores para auxiliar al profesor a fomentar la creatividad en clase.

Palabras-clave: creatividad; coordinador pedagógico; escuela; prácticas docentes; maestro
\end{abstract}

A importância da criatividade nos processos de ensino e aprendizagem tem sido crescentemente reconhecida desde os anos 50, quando Guilford (1950), em seu discurso presidencial na Associação Americana de Psicologia, chamou a atenção para a necessidade de se identificar e desenvolver o talento criativo, ao mesmo tempo em que sublinhou que o desenvolvimento da criatividade era seriamente desencorajado no sistema educacional. Desde então, fatores que se relacionam ao florescimento da criatividade em sala de aula, facilitando-o ou inibindo-o, têm sido objeto de discussão e estudo em número crescente. Uma justificativa para tal interesse relaciona-se ao papel central da criatividade para o progresso das sociedades e ainda a consciência 
de que é necessário preparar o aluno para lidar com os desafios e demandas típicas da sociedade do conhecimento. Nesta, a complexidade, incerteza e ritmo acelerado de mudança estão por exigir, entre outras competências e habilidades, a capacidade de pensar de forma criativa e inovadora (Alencar, 2015; Beghetto, 2010; Treffinger, Schoonover, \& Selby, 2013; Wechsler \& Nakano, 2011). Segundo Csikszentmihalyi (1999), o fenômeno da criatividade deve ser compreendido como um processo sistêmico e contínuo, resultante tanto de fatores intraindividuais quanto ambientais. Para esse autor, questionar o que é criatividade é tão relevante quanto perguntar "onde está a criatividade".

No que tange ao desenvolvimento da criatividade no contexto educacional, observa-se que, paralelamente ao reconhecimento da importância de se incentivar na escola a expressão da capacidade de criar do aluno, como atestam documentos governamentais (Ministério da Educação, 1997, 1998, 2010; Smith-Bingham, 2006) e sinalizam pesquisadores que têm se dedicado ao estudo da criatividade (Alencar \& Fleith, 2009, 2016; Alencar, Braga, \& Marinho, 2016; Hosseini, 2011; Kaufmann, Beghetto, \& Pourjalali, 2011; Omdal \& Graefe, 2017; Renzulli, 2016; Romo, 2012; Sternberg, 2015; Wechsler \& Souza, 2011), há numerosos fatores que contribuem para cercear ou limitar a expressão da criatividade em sala de aula. Procedimentos de ensino convergente, extensão do conteúdo a ser ensinado em um período curto de tempo, normas institucionais reticentes à inovação no que diz respeito a práticas pedagógicas são alguns desses fatores. Por outro lado, pesquisas realizadas com professores de diferentes níveis de ensino (Alencar \& Fleith, 2008, 2010; Carvalho \& Alencar, 2004; Harris \& Bruin, 2017; Mariani \& Alencar, 2005; Wechsler \& Nakano, 2007), a quem foi solicitado apontar elementos cerceadores à criatividade em sala de aula, indicam que foram elementos relacionados aos alunos aqueles mais apontados pelos docentes, seja na educação fundamental, seja na superior (Alencar \& Fleith, 2008, 2010; Lima \& Alencar, 2014; Souza \& Alencar, 2006). Quanto às estratégias que melhor favorecem o desenvolvimento da criatividade dos educandos, foram os procedimentos didáticos que facilitam a aprendizagem dos alunos os mais sinalizados (Carvalho \& Alencar, 2004) e ainda a liberdade e paixão pelo trabalho como facilitadores à expressão criativa na prática pedagógica (Mariani \& Alencar, 2005).

A literatura registra poucos estudos com outros partícipes da equipe pedagógica, como gestores e coordenadores pedagógicos, que incluem entre suas atribuições a de assistir ao professor no trabalho pedagógico. No que diz respeito ao coordenador pedagógico, uma de suas principais funções é coordenar, assessorar e avaliar as atividades pedagógicas, prestando assistência aos docentes em sua prática em sala de aula (Libâneo, Oliveira, \& Toschi, 2005). Dessa forma, constitui-se também em elemento-chave a contribuir para o estímulo ao desenvolvimento e expressão da criatividade discente. Nota-se, entretanto, que apenas uma pesquisa foi localizada com amostra de coordenadores pedagógicos (Oliveira \& Alencar, 2012) tendo como foco a criatividade no contexto escolar. Neste estudo, 12 coordenadores pedagógicos de escolas particulares do ensino fundamental foram entrevistados sobre a importância do desenvolvimento/expressão da criatividade docente e elementos associados à criatividade em sala de aula. Os resultados indicaram que para todos os coordenadores a criatividade deveria ser presente no contexto escolar e, em especial, no trabalho do professor. Isso, de acordo com os participantes do estudo, teria impacto positivo no interesse e na aprendizagem do aluno, entre outras vantagens.

Tendo a literatura consultada nas bases SciELO, PePSIC e Portal CAPES indicado escassez de estudos empíricos, publicados nos últimos cinco anos, envolvendo dados sobre criatividade coletados com outros profissionais da equipe pedagógica da escola para além do professor, bem como o relevante papel do coordenador pedagógico na orientação da prática docente, desenvolveu-se o presente estudo. Este teve como objetivos investigar: (a) fatores apontados por coordenadores pedagógicos como entraves que dificultam o professor a promover o desenvolvimento da criatividade de seus alunos; (b) procedimentos que poderiam utilizar para apoiar o professor do ensino fundamental na promoção de condições favoráveis à criatividade em sala de aula; (c) possíveis diferenças entre coordenadores pedagógicos das instituições de ensino públicas e particulares nas variáveis pesquisadas.

\section{Método}

\section{Participantes}

Participaram do estudo 66 coordenadores pedagógicos, sendo sete $(10,6 \%)$ do sexo masculino e os demais $(n=59 ; 89,4 \%)$ do sexo feminino. Da amostra total, $35(53,0 \%)$ atuavam em escolas públicas e $31(47,0 \%)$ em escolas particulares de distintas regiões administrativas do Distrito Federal. Os participantes tinham curso superior completo e a maior parte deles $(n=41 ; 62,1 \%)$ 
havia cursado especialização. A idade variou entre 26 e 62 anos $(M=39,33$; $D P=7,57)$, com tempo de experiência entre 1 e 26 anos $(M=6,63 ; D P=5,73)$. Dois coordenadores deixaram de informar a idade, quatro o tempo de experiência e um o grau de escolaridade.

\section{Instrumento e Procedimento de Coleta de Dados}

Foi utilizado um questionário composto de três partes. A primeira para levantamento de dados biográficos dos respondentes (gênero, idade, experiência docente e em coordenação pedagógica de instituições de ensino e formação acadêmica) e obter informações a respeito do tipo e local da escola em que atuam. A segunda, composta por uma checklist com distintos fatores que podem se constituir em barreiras à promoção da criatividade discente pelo professor, com instrução para assinalar aqueles com que concordavam serem entraves a essa promoção. Esse instrumento foi utilizado anteriormente em estudos com professores do ensino fundamental (Alencar \& Fleith, 2008) e gestores de instituições de ensino fundamental (Alencar, Fleith, Boruchovitch, \& Borges, 2015). Ele inclui distintos itens referentes ao aluno, ao professor, ao currículo e à escola, entre outros aspectos. Essa checklist foi construída com base em estudos teóricos e empíricos (Alencar \& Fleith, 2003; Cropley, 2005; Fleith, 2000; Mariani \& Alencar, 2005; Morgan \& Foster, 1999), a respeito de fatores facilitadores e inibidores à criatividade no contexto educacional.

Complementam a referida checklist as seguintes questões abertas:

(1) Em sua opinião, o que um coordenador pedagógico de instituição de ensino fundamental pode fazer para apoiar o professor na promoção de um ambiente em sala de aula propício ao desenvolvimento da criatividade do aluno?

(2) Que práticas pedagógicas o(a) senhor(a) considera que o professor poderia utilizar para favorecer o desenvolvimento da criatividade do aluno?

(3) O projeto pedagógico desta instituição contempla a promoção da criatividade do aluno? Em caso positivo, explicite o que o projeto sinaliza a esse respeito.

(4) Como eliminar os fatores que o(a) senhor(a) considera que têm dificultado o professor a favorecer o desenvolvimento da capacidade de criar de seus alunos?
Antes de sua aplicação na amostra do presente estudo, foi realizado um estudo piloto com três coordenadores pedagógicos (dois lotados em instituição particular e um em instituição pública de ensino fundamental), no sentido de se assegurar a clareza das instruções e identificar possíveis mudanças na estrutura do conteúdo do instrumento de pesquisa. Não foram identificadas correções ou mudanças necessárias no questionário.

Os dados foram coletados pela primeira pesquisadora, por estudantes de pós-graduação (mestrado em Educação e Psicologia) e bolsistas de Iniciação Científica. Embora tivesse sido prevista a aplicação do instrumento de forma individual na presença do pesquisador, nem sempre isso ocorreu, dada a incompatibilidade de horário participante/pesquisador. Ademais, no caso de oito coordenadores, a aplicação se deu durante um encontro de coordenadores promovido pela Diretoria Regional de Ensino do Distrito Federal. A participação no estudo foi voluntária, tendo sido assegurado aos participantes o caráter confidencial das respostas fornecidas e informado que os dados seriam analisados coletivamente, cumprindo assim as exigências éticas legais.

\section{Análise dos Dados}

Foram calculadas a frequência e porcentagem em cada item da checklist (total e por tipo de instituição de ensino). O qui-quadrado foi utilizado para análise das diferenças entre coordenadores pedagógicos de instituições públicas e particulares.

Para análise das questões abertas, foi utilizada análise de conteúdo, seguindo as orientações de Bardin (2004). Foi efetuada a categorização das respostas por meio de classificação das unidades de significação, levantando-se, a seguir, a sua frequência e porcentagem. A construção inicial de categorias, com suas respectivas frequências, foi feita pela terceira autora deste estudo e uma bolsista de IC. Uma segunda análise foi realizada pela primeira autora deste artigo, quando se diminuiu o número de categorias propostas e se reavaliaram as categorias nas quais melhor se enquadravam algumas respostas dos participantes. Após essa etapa, reuniram-se novamente os que participaram da análise de dados, com vistas a discutir possíveis discrepâncias na classificação de algumas respostas, buscando um acordo.

\section{Resultados}

Constatou-se que vários fatores foram apontados por um percentual expressivo de coordenadores 
pedagógicos como entraves ao professor para promover o desenvolvimento da criatividade dos alunos. Os mais sinalizados foram desconhecimento de práticas pedagógicas que poderiam ser utilizadas para propiciar o desenvolvimento da criatividade dos alunos ( $n$ $=52 ; 78,8 \%)$; insegurança para testar novas práticas pedagógicas ( $n=45 ; 68,2 \%$ ); baixo reconhecimento do trabalho do professor $(n=43 ; 65,2 \%)$; desconhecimento de textos (livros e/ou artigos) a respeito de como implementar a criatividade em sala de aula $(n=$ 42; 63,6\%) e elevado número de alunos em sala de aula $(n=42 ; 63,6 \%)$. Por outro lado, os fatores menos apontados foram qualidade dos livros didáticos adotados na escola $(n=16 ; 24,2 \%)$; falta de oportunidade para realizar atividades fora da sala de aula $(n=24 ; 36,4 \%)$ e falta de autonomia na forma de conduzir as atividades docentes $(n=25 ; 37,9 \%)$.

Foram analisadas as diferenças entre coordenadores de instituições públicas e particulares de ensino nos fatores apontados como entraves ao professor para promover o desenvolvimento da criatividade discente (ver Tabela 1). Constatou-se que um percentual significativamente superior de coordenadores pedagógicos de instituições públicas, comparativamente ao de escolas particulares, indicou a presença de alunos indisciplinados que perturbam o trabalho docente, escassez de material didático disponível na escola, desinteresse do aluno pelo conteúdo ministrado e alunos com dificuldades de aprendizagem em sala de aula como fatores que dificultam ao professor promover o desenvolvimento da criatividade de seus alunos. Por outro lado, desconhecimento de práticas pedagógicas que poderiam ser utilizadas para propiciar o desenvolvimento da criatividade dos alunos, desconhecimento de textos a respeito de como implementar a criatividade em sala de aula, poucas oportunidades para discutir e trocar ideias com colegas de trabalho sobre estratégias instrucionais e falta de autonomia na forma de conduzir as atividades docentes foram significativamente mais apontados pelos coordenadores de escolas particulares.

A análise das respostas obtidas à primeira questão aberta "Em sua opinião, o que um coordenador pedagógico pode fazer para apoiar o professor do ensino fundamental na promoção de um ambiente em sala de aula propício ao desenvolvimento da criatividade do aluno?" indicou que elas se enquadravam

Tabela 1

Fatores Inibidores à Criatividade Discente Segundo Coordenadores Pedagógicos

\begin{tabular}{|c|c|c|c|c|c|c|}
\hline \multirow{3}{*}{ Barreiras } & \multicolumn{4}{|c|}{ Escola } & \multirow{3}{*}{$\chi^{2}$} & \multirow{3}{*}{$p$} \\
\hline & \multicolumn{2}{|c|}{$\begin{array}{l}\text { Pública } \\
(\mathrm{N}=35)\end{array}$} & \multicolumn{2}{|c|}{ Particular $(\mathrm{N}=31)$} & & \\
\hline & $f$ & $\%$ & $f$ & $\%$ & & \\
\hline $\begin{array}{l}\text { Desconhecimento de práticas pedagógicas } \\
\text { que poderiam ser utilizadas para propiciar o } \\
\text { desenvolvimento da criatividade dos alunos. }\end{array}$ & 23 & 65,7 & 29 & 93,5 & 7,62 & 0,006 \\
\hline $\begin{array}{l}\text { Desconhecimento de textos (livros e/ou artigos) } \\
\text { a respeito de como implementar a criatividade em } \\
\text { sala de aula. }\end{array}$ & 18 & 51,4 & 24 & 77,4 & 4,80 & 0,028 \\
\hline $\begin{array}{l}\text { Presença de alunos indisciplinados que perturbam } \\
\text { o trabalho docente. }\end{array}$ & 25 & 71,4 & 8 & 25,8 & 13,69 & 0,0001 \\
\hline Desinteresse do aluno pelo conteúdo ministrado. & 23 & 65,7 & 9 & 29,0 & 8,86 & 0,003 \\
\hline Escassez de material didático disponível na escola. & 22 & 62,9 & 9 & 29,0 & 7,55 & 0,006 \\
\hline $\begin{array}{l}\text { Poucas oportunidades para discutir e trocar } \\
\text { ideias com colegas de trabalho sobre estratégias } \\
\text { instrucionais. }\end{array}$ & 10 & 28,6 & 21 & 67,7 & 10,13 & 0,001 \\
\hline $\begin{array}{l}\text { Alunos com dificuldades de aprendizagem em sala } \\
\text { de aula. }\end{array}$ & 22 & 62,9 & 7 & 22,6 & 10,83 & 0,001 \\
\hline $\begin{array}{l}\text { Falta de autonomia na forma de conduzir as } \\
\text { atividades docentes. }\end{array}$ & 8 & 22,9 & 17 & 54,8 & 7,15 & 0,008 \\
\hline
\end{tabular}


em seis categorias, denominadas (a) Formação/Capacitação; (b) Orientação/Apoio/Incentivo; (c) Recursos Didáticos e Materiais; (d) Discussão/Troca de Experiências; (e) Alunos; e (f) Outras (ver Tabela 2). Como mostra a tabela, as duas categorias com maior número de respostas dadas por coordenadores de instituições públicas de ensino foram Orientação/Apoio/Incentivo ( $\mathrm{f}=12)$ e Discussão/Troca de Experiências ( $\mathrm{f}=13$ ). Por outro lado, entre os coordenadores de instituições particulares foram Formação/Capacitação $(f=21)$ e Orientação/Apoio/Incentivo ( $\mathrm{f}=18)$. Ademais, entre os 66 coordenadores pedagógicos, um deles que trabalhava em instituição pública respondeu que quase nada é possível fazer, uma vez que "o espaço físico dificilmente pode ser alterado e quando acontece não tem recurso financeiro".

Seguem exemplos de respostas que ilustram as diferentes categorias:

a) Formação/Capacitação: promover processos de formação continuada em serviço; oferecer cursos de reciclagem e aperfeiçoamento para os professores.

b) Orientação/Apoio/Incentivo: acompanhar e orientar o professor em encontros individuais; participar efetivamente da coordenação do professor, ajudando-o no desenvolvimento de suas ideias e projetos, apoiando-o quando necessitar, orientando, dando novas ideias.

c) Recursos Humanos/Didáticos/Materiais: oferecer recursos materiais para sua prática em sala de aula; fornecer material didático variado e adequado. d) Discussão/Troca de Experiência: promover encontros entre os professores para que possam trocar experiências; propiciar momentos de discussão e reflexão nas coordenações, no momento de elaborar planejamentos.

e) Alunos: reduzir o número de alunos em sala de aula; conhecer o perfil dos alunos.

f) Outras: aproximar-se da área pedagógica, interessando-se, conhecendo, opinando e promovendo meios para que os objetivos do projeto político pedagógico sejam alcançados.

A análise das respostas obtidas à segunda questão aberta, referente à indicação de práticas pedagógicas que poderiam ser utilizadas pelos professores para favorecer o desenvolvimento da criatividade, resultou na identificação de três categorias principais. A primeira diz respeito a recursos didáticos/materiais, como utilização de recursos multimídia, mapas, sucata; a segunda categoria, a que se denominou "atividades diversificadas", inclui trabalhos em grupos, jogos, dramatizações, debates, pesquisa de campo; e a terceira categoria foi denominada "alunos", incluindo respostas em que o foco central eram estratégias de ensino envolvendo o aluno, estimulando-o a se expressar, participar, refletir e criar (ver Tabela 3). Aproximadamente metade das respostas dadas se concentrou na categoria Atividades Diversificadas. Um coordenador de instituição particular não respondeu à questão.

Respostas que ilustram as distintas categorias são apresentadas a seguir:

Tabela 2

Frequência e Porcentagem de Respostas à Primeira Questão Aberta por Parte de Coordenadores Pedagógicos

\begin{tabular}{lcccccc}
\hline \multirow{2}{*}{ Categorias } & \multicolumn{5}{c}{ Tipo de Escola } \\
\cline { 2 - 7 } & \multicolumn{2}{c}{$\begin{array}{c}\text { Pública } \\
(n=35)\end{array}$} & \multicolumn{2}{c}{$\begin{array}{c}\text { Particular } \\
(n=31)\end{array}$} & \multicolumn{2}{c}{ Total } \\
\cline { 2 - 7 } & $f$ & $\%$ & $f$ & $\%$ & $f$ & $\%$ \\
\hline Formação/Capacitação & 10 & 18,52 & 21 & 33,33 & 31 & 26,50 \\
Orientação/Apoio/Incentivo & 12 & 22,22 & 18 & 28,57 & 30 & 25,64 \\
Recursos Humanos/ Didáticos/Materiais & 8 & 14,82 & 10 & 15,87 & 18 & 15,38 \\
Discussão/Troca de Experiências & 13 & 24,07 & 8 & 12,70 & 21 & 17,95 \\
Alunos & 5 & 9,26 & 2 & 3,18 & 7 & 5,98 \\
Outras & 6 & 11,11 & 4 & 6,35 & 10 & 8,55 \\
Total & 54 & 100 & 63 & 100 & 117 & 100 \\
\hline
\end{tabular}


Tabela 3

Frequência e Porcentagem de Respostas à Segunda Questão Aberta por Parte de Coordenadores Pedagógicos

\begin{tabular}{lcccccc}
\hline \multirow{2}{*}{ Categorias } & \multicolumn{9}{c}{ Tipo de Escola } \\
\cline { 2 - 7 } & \multicolumn{2}{c}{ Pública $(n=35)$} & \multicolumn{2}{c}{ Particular $(n=31)$} & \multicolumn{2}{c}{ Total } \\
\cline { 2 - 7 } & $f$ & $\%$ & $f$ & $\%$ & $f$ & $\%$ \\
\hline Atividades Diversificadas & 25 & 52,08 & 24 & 46,15 & 49 & 49,00 \\
Aluno & 11 & 22,92 & 15 & 28,85 & 26 & 26,00 \\
Recursos Didáticos/Materiais & 9 & 18,75 & 7 & 13,46 & 16 & 16,00 \\
Outras & 3 & 6,25 & 6 & 11,54 & 9 & 9,00 \\
Total & 48 & 100 & 52 & 100 & 100 & 100 \\
\hline
\end{tabular}

a) Atividades Diversificadas: utilização de dinâmicas, jogos vivenciais; as artes em geral: plásticas, cênicas, música e outras.

b) Alunos: não dar respostas prontas, estimular novas ideias, deixar que os alunos procurem soluções par a situações-problema; escutar sempre os alunos; valorizar suas ideias.

c) Recursos Didáticos/Materiais: usar recursos multimídia, como data show, computador, caneta óptica; utilizar materiais concretos, jogos, filmes.

d) Outras: promover a afetividade; o professor ser referência de prática de leitura e investigação.

No que diz respeito ao projeto pedagógico e se o mesmo contempla a promoção da criatividade do aluno, uma análise das respostas obtidas indicou que 25 $(80,64 \%)$ coordenadores de instituições particulares e $24(68,57 \%)$ de instituições públicas responderam afirmativamente. Os demais responderam negativamente, deixaram de responder, informaram que apenas parcialmente ou que o referido projeto ainda não foi colocado em prática. Uma análise das respostas referentes ao que o projeto pedagógico sinaliza a respeito de criatividade apontou que elas se distribuíram em três categorias principais: Atividades Diversificadas, Aluno e Professor (ver Tabela 4).

Seguem respostas que ilustram as distintas categorias:

a) Atividades Diversificadas: realização de feiras, exposições e demais práticas que impulsionam a criatividade do aluno; Projetos do laboratório de aprendizagem; Projeto de Xadrez; Projeto Recreio Legal; Projetos de literatura. Projetos interdisciplinares. b) Aluno: no projeto pedagógico é valorizada a criatividade do aluno; participação do aluno na construção de normas e condutas; dar muita autonomia ao aluno.

c) Professor: promover a formação do docente; oportunizar ao professor a autonomia para criar estratégias diversificadas para o trabalho; oferecer subsídios onde o professor pode escolher sua metodologia e divulgá-la.

d) Outras: o projeto tem como meta a promoção de condições que facilitem o aprendizado e que preparem o aluno para a vida profissional; propõe o trabalho com a diversidade, ou seja, o respeito às diferenças e a busca de inclusão da pessoa humana; trabalhamos na linha da construção do conhecimento que favorece o pensar, o raciocínio.

Quanto à última questão aberta "Como eliminar os fatores que o(a) senhor(a) considera que têm dificultado ao professor favorecer o desenvolvimento da capacidade de criar de seus alunos, apontados na página anterior?", uma análise das respostas obtidas indicou que elas se enquadravam nas categorias relacionadas na Tabela 5. Como indicado na tabela, $18,75 \%$ das respostas de coordenadores de instituições públicas foram relativas a reflexões sobre a prática/troca de experiências e 16,67\% referentes a orientação/apoio/incentivo. Por outro lado, $22,22 \%$ das respostas de coordenadores de instituições particulares diziam respeito a orientação/apoio/incentivo. Constatou-se ainda que um coordenador de instituição particular e outro de instituição pública de ensino não responderam à questão. Ademais, dois coordenadores pedagógicos de instituições particulares ressaltaram que é algo impossível ou muito complexo e um coordenador de instituição 
Tabela 4

Propostas Previstas no Projeto Pedagógico para Promover a Criatividade do Aluno Apresentadas por Coordenadores Pedagógicos

\begin{tabular}{lcccccc}
\hline \multirow{2}{*}{ Categorias } & \multicolumn{5}{c}{ Tipo de Escola } \\
\cline { 2 - 7 } & \multicolumn{2}{c}{ Pública $(n=35)$} & \multicolumn{2}{c}{ Particular $(n=31)$} & \multicolumn{2}{c}{ Total } \\
\cline { 2 - 7 } & $f$ & $\%$ & $f$ & $\%$ & $f$ & $\%$ \\
\hline Atividades Diversificadas & 11 & 44,00 & 11 & 34,38 & 22 & 38,60 \\
Aluno & 6 & 24,00 & 11 & 34,38 & 17 & 29,82 \\
Professor & 3 & 12,00 & 5 & 15,62 & 8 & 14,04 \\
Outras & 5 & 20,00 & 5 & 15,62 & 10 & 17,54 \\
Total & 25 & 100 & 32 & 100 & 57 & 100 \\
\hline
\end{tabular}

Tabela 5

Propostas Apresentadas por Coordenadores para Eliminar Fatores ao Desenvolvimento da Criatividade dos Alunos

\begin{tabular}{lcccccc}
\hline \multirow{2}{*}{ Categorias } & \multicolumn{5}{c}{ Tipo de Escola } \\
\cline { 2 - 7 } & \multicolumn{2}{c}{ Pública $(n=35)$} & Particular $(n=31)$ & \multicolumn{2}{c}{ Total } \\
\cline { 2 - 7 } & $f$ & $\%$ & $f$ & $\%$ & $f$ & $\%$ \\
\hline Formação/Capacitação & 5 & 10,42 & 14 & 25,93 & 19 & 18,63 \\
Orientação/Apoio/Incentivo & 8 & 16,67 & 12 & 22,22 & 20 & 19,62 \\
Recursos Didáticos/Materiais/Humanos & 7 & 14,58 & 2 & 3,70 & 9 & 8,82 \\
Reflexões sobre a Prática/ Troca de Experiências & 9 & 18,75 & 8 & 14,81 & 17 & 16,67 \\
Alunos & 5 & 10,42 & 3 & 5,56 & 8 & 7,84 \\
Tempo /Incentivo Salariais & 2 & 4,16 & 4 & 7,41 & 6 & 5,88 \\
Outras & 12 & 25,00 & 11 & 20,37 & 23 & 22,54 \\
Total & 48 & 100 & 54 & 100 & 102 & 100 \\
\hline
\end{tabular}

pública e outro de escola particular informaram que não sabiam o que fazer, tendo dois outros de instituição pública utilizado o espaço para apontar problemas que afetam a atuação do professor, como, por exemplo, turmas excessivamente cheias, alunos heterogêneos e falta de motivação do professor.

Seguem exemplos de respostas que ilustram cada uma das categorias:

a) Formação/Capacitação: formação continuada por meio de reuniões pedagógicas, seminários e workshops; cursos de formação continuada para inovações e conhecimentos das práticas.

b) Orientação/Apoio/Incentivo: orientações de como trabalhar com alunos que têm baixo rendimento; acompanhando diariamente a prática pedagógica; estimulando e incentivando a inovar a prática pedagógica.

c) Trabalho em Equipe: construção coletiva do trabalho pedagógico; trabalhando em equipe e não por competitividade.

d) Recursos Didáticos/Materiais/Humanos: adquirir novos materiais didáticos; incentivo de recursos didáticos e pedagógicos, como materiais, jogos, espaço físico.

e) Reflexões sobre a Prática/Troca de Experiências: levá-lo a refletir sobre sua prática; utilização adequada do tempo de coordenação para discussão, formação, troca de experiências, grupos de estudo, etc.

f) Valorização do Professor: valorizando o profissional, não só na questão salarial e sim no dia a dia; é 
indispensável a luta por políticas públicas que valorizam a educação e o educador.

g) Alunos: reduzir o número de alunos por turma e colocar monitores; buscar as razões do desinteresse do aluno.

h) Tempo/Incentivo Salarial: que o professor possa ter mais tempo para se dedicar à profissão e melhorar salários; precisa de um tempo maior para planejamento, estudo, pesquisa e coordenações coletivas.

i) Gestão Democrática: promovendo uma gestão participativa e de confiança; uma gestão realmente democrática, com a participação de todos.

j) Conteúdo: reestruturar os conteúdos; agrupar o conteúdo buscando o que de fato é essencial.

k) Outros: integrar o "renda minha" às notas dos alunos, não só à sua frequência. Um governo que atenda melhor às necessidades da escola e do aluno.

\section{Discussão}

Este estudo teve como objetivos centrais investigar, entre coordenadores pedagógicos, fatores que dificultam ao professor do ensino fundamental promover o desenvolvimento da criatividade discente e procedimentos que os coordenadores poderiam fazer uso junto aos professores para facilitar o estímulo à criatividade em sala de aula. No que diz respeito ao primeiro objetivo, os resultados revelaram que o fator mais apontado pelos coordenadores foi o desconhecimento pelos professores de procedimentos que poderiam ser utilizados em sala para estimular a criatividade discente. Outros elementos sinalizados por um número expressivo de participantes foram a insegurança docente para colocar em prática novas práticas pedagógicas e o desconhecimento por parte do professor de textos referentes a como assegurar a presença da criatividade em sala de aula. Resultados similares a este foram encontrados em estudo anterior com gestores (Alencar, Fleith, Boruchovitch, \& Borges, 2015) no qual a mesma checklist foi utilizada e por Oliveira e Alencar (2010) em pesquisa com nove gestores de instituições de ensino fundamental. Tais dados parecem sugerir que gestores e coordenadores de instituições de ensino fundamental estão de acordo quanto à formação limitada do professor no que concerne à criatividade e como promovê-la em sala de aula.

De fato, apesar de ser reconhecida a importância de se incentivar o desenvolvimento da capacidade de criar dos alunos, constituindo mesmo tal desenvolvimento, um dos objetivos destacado em documentos governamentais referentes às diretrizes curriculares (Ministério da Educação, 1997, 1998, 2010), a criatividade não é um tema que tem recebido a atenção devida nos cursos de formação de professores. Ademais, em muitos desses cursos, o modelo de ensino predominante está em dissonância com uma proposta educacional voltada para o desenvolvimento do potencial para criar, com limitado espaço para a expressão da criatividade dos futuros professores (Alencar, 2015, 2016; Alencar, Braga, \& Marinho, 2016; Beghetto \& Kaufman, 2010; Martínez, 2006; Sternberg, 2015).

Em contraste com os resultados deste estudo, pesquisas realizadas com professores do ensino fundamental e do ensino superior indicaram que, para os docentes, os principais fatores inibidores à promoção de condições propícias ao desenvolvimento da criatividade em sala de aula diziam respeito ao aluno, como desinteresse pelo conteúdo ministrado e alunos com dificuldades de aprendizagem (Alencar \& Fleith, 2008; Carvalho \& Alencar, 2004; Nakano, 2009). Essa discrepância possivelmente reflete uma dificuldade do professor em admitir o seu escasso conhecimento a respeito de criatividades nos processos de ensino-aprendizagem, aspecto esse observado por coordenadores pedagógicos, em sua atuação junto a corpo docente.

Diferenças significativas entre coordenadores de instituições de ensino públicas e particulares foram observadas em vários itens da checklist. Quase totalidade dos coordenadores de escolas particulares apontou o desconhecimento pelos docentes de práticas pedagógicas promotoras da criatividade e grande maioria deles indicou o desconhecimento pelos professores de textos relacionados ao estímulo à criatividade em sala de aula, além de poucas oportunidades para discutir ideias com colegas sobre estratégias instrucionais, tendo ainda mais da metade sinalizado falta de autonomia pelos docentes referente a como conduzir as atividades em sala de aula. Tais resultados são mais um fator que chama a atenção para a necessidade de uma revisão nas propostas curriculares dos cursos de formação de professores no sentido de incluir a criatividade como tema a ser trabalhado em sua formação, como tem sido sublinhado por diversos autores, como Alencar e Fleith (2009), Wechsler e Souza (2011) Martínez (2006), entre outros. Os dados sugerem também a necessidade de se revisar a cultura institucional dominante em escolas, onde predominam normas rígidas a respeito de como deve o professor conduzir as atividades em classe, por ser 
este um limitador àqueles docentes desejosos de inovar a sua prática, como sublinhado por mais da metade de coordenadores de instituições particulares de ensino.

Percentual significativamente superior de coordenadores de escolas públicas, comparativamente ao de escolas particulares, sinalizaram, como elementos que dificultam ao professor estimular a criatividade em sala de aula, fatores relacionados ao aluno (alunos indisciplinados, com dificuldades de aprendizagem e desinteressados no conteúdo ministrado), além de escassez de material didático. Esses resultados podem espelhar estereótipos acerca de alunos que frequentam escolas públicas como sendo aqueles provenientes de status socioeconômico baixo e, consequentemente, não possuírem condições ideais de estudo ou suporte familiar para realização das atividades escolares. Nesse sentido, é importante a condução de pesquisas que possam investigar em que medida características dos alunos, como desinteresse e indisciplina, entre outras, geram ou, por outro lado, são frutos de práticas educativas pouco estimuladoras da criatividade. Ademais, o conteúdo a ser coberto durante o ano letivo, além de extenso, é boa parte dele muito distante do universo que circunda os discentes. Esses elementos associados à precariedade de recursos didáticos disponíveis na escola têm impacto na aprendizagem e motivação discentes, além de contribuir para dificultar a promoção de um ambiente onde a criatividade possa melhor florescer.

Ao serem inquiridos a respeito do que poderiam fazer para auxiliar o professor na tarefa de facilitar o desenvolvimento da criatividade discente, os coordenadores sinalizaram a oferta de cursos e formação em serviço, além de apoio e orientação ao docente. Esses dados estão em congruência com os obtidos por meio da checklist, no que tange à necessidade de complementar a formação do professor. Em relação ao apoio ao docente, Collard e Looney (2014) ressaltam a importância de que os professores sejam encorajados pelos colegas e demais profissionais da instituição a correr riscos, a apresentar características como curiosidade, imaginação e flexibilidade, e a estabelecer parcerias entre escola, famílias e comunidade. Quanto às práticas pedagógicas a serem utilizadas pelos docentes para o incentivo da criatividade em sala de aula, atividades diversificadas relacionadas às artes, uso de dinâmicas e jogos vivenciais, além de oficinas de aprendizagem foram os mais apontados. Tais dados sugerem que, de forma similar ao observado em pesquisa com docentes (Fleith, 2000) e gestores (Alencar et al., 2015), também os coordenadores têm um conhecimento limitado a respeito de estratégias e técnicas de estimulação da criatividade.

Uma análise das respostas relativas ao projeto pedagógico e o que nele estava previsto no tocante à criatividade revelou que, embora um alto percentual tenha respondido afirmativamente, o conteúdo apresentado era bastante superficial e genérico, constatando-se ainda respostas que não diziam respeito à criatividade, mas a outros aspectos, como inclusão e aprendizagem. Esse é mais um dado que chama a atenção para lacunas a serem sanadas na formação não somente de professores, mas também de outros profissionais da equipe pedagógica. É importante também destacar que, para se assegurar o florescimento da criatividade em sala de aula, não é suficiente apenas capacitar os professores. Outros fatores, como condições de trabalho, estrutura da escola, cultura institucional predominante na escola, recursos didáticos disponíveis ao professor, elementos relacionados ao currículo, devem ser levados em conta.

\section{Considerações Finais}

Em que pesem as contribuições da presente pesquisa no que se refere a chamar a atenção para elementos que cerceiam ou facilitam a expressão da criatividade em sala aula sob a ótica de coordenadores pedagógicos, há limitações do estudo a serem apontadas. Uma delas diz respeito à amostra utilizada, que se caracteriza como de conveniência, com um número limitado de participantes. Uma segunda limitação foi ter sido a coleta de dados realizada tanto de forma individual quanto coletiva, tendo ainda alguns participantes deixado de responder o questionário na presença do pesquisador. Esses elementos limitam as possibilidades de generalização ou validade externa do estudo. Como sugestões para pesquisas futuras, poderse-iam apontar ampliar o número de participantes, utilizar entrevistas para aprofundamento dos aspectos examinados, realizar estudos comparativos com amostras de representantes de toda a equipe pedagógica de instituições de ensino, investigar possíveis diferenças entre coordenadores com maior e menor experiência profissional e entre os que atuam em instituições de ensino consideradas inovadoras e tradicionais.

No que diz respeito às implicações práticas da pesquisa, recomenda-se a divulgação de textos com embasamento científico, bem como a realização de oficinas e cursos que esclareçam e orientem coordenadores pedagógicos e demais membros da equipe pedagógica da instituição escolar a como estimular a criatividade 
em sala aula. Sugere-se, ainda, que as intervenções realizadas junto aos professores não se restrinjam aos encontros em si, mas que tanto o planejamento quanto a realização das atividades em sala de aula, por parte dos docentes, sejam discutidos e acompanhados por um especialista em criatividade, no sentido de promover maior articulação entre prática e teoria.

\section{Referências}

Alencar, E. M. L. S. (2015). Promoção da criatividade em distintos contextos: Entraves e desafios. Em M. F. Morais, L. C. Miranda \& S. M. Wechsler (Eds.), Criatividade. Aplicaşões práticas em distintos contextos (pp. 15-32). São Paulo: Vetor.

Alencar, E. M. L. S. (2016). O papel da escola no desenvolvimento da criatividade. Pátio Ensino Fundamental, 20(79), 6-9.

Alencar, E. M. L. S., Braga, N. P., \& Marinho, C. D. (2016). Como desenvolver o potencial criador $\left(12^{\mathrm{a}} \mathrm{ed}.\right)$. Petrópolis: Vozes.

Alencar, E. M. L. S., \& Fleith, D. S. (2003). Criatividade. Múltiplas perspectivas (1 ${ }^{\mathrm{a}}$. ed.). Brasília: Editora UnB.

Alencar, E. M. L. S., \& Fleith, D. S. (2008). Barreiras à promoção da criatividade no ensino fundamental. Psicologia: Teoria e Pesquisa, 24(1), 59-65. doi:10.1590/ S0102-37722008000100007

Alencar, E. M. L. S., \& Fleith, D. S. (2009). Criatividade. Múltiplas perspectivas ( $3^{a}$ ed.). Brasília: Editora UnB.

Alencar, E. M. L. S., \& Fleith, D. S. (2010). Criatividade na educação superior. Avaliação, 15(2), 201-206. doi:10.1590/S1414-40772010000200011

Alencar, E. M. L. S., \& Fleith, D. S. (2016). Relationships between motivation, cognitive styles and perception of teaching practices for creativity. Estudos de Psicologia, 33(3), 503-513. doi:10.1590/1982-027520160003000013

Alencar, E.M.L. S., Fleith, D. S., Boruchovitch, E., \& Borges, C.N.(2015).Criatividadenoensino fundamental: fatores inibidores e facilitadores segundo gestores educacionais. Psicologia: Teoria e Pesquisa, $31(1), 105-$ 114. doi:10.1590/0102-37722015011849105114

Bardin, L. (2004). Análise de conteúdo (3ª ed.). Lisboa: Edições 70.

Beghetto, R. A. (2010). Creativity in the classroom. Em J. C. Kaufman \& R. J. Sternberg (Eds.), The
Cambridge handbook of creativity (pp. 447-466). New York: Cambridge University Press.

Beghetto, R. A., \& Kaufman, J. C. (2010). (Eds.). Nurturing creativity in the classroom. New York: Cambridge University Press.

Carvalho, O., \& Alencar, E. M. L. S. (2004). Elementos favorecedores e inibidores da criatividade na prática docente, segundo professores de Geografia. Psico, 35, 213-221. Recuperado de: http:// revistaseletronicas.pucrs.br/fo/ojs/index.php/ revistapsico/issue/archive

Collard, P., \& Looney, J. (2014). Nurturing creativity in education. European Journal of Education, 49(3), 348364. doi:10.1111/ejed.12090

Cropley, A. J. (2005). Creativity in education \& learning. London: RoutledgeFalmer.

Fleith, D. S. (2000). Teacher and student perceptions of creativity in the classroom environment. Roeper Review, 22(3), 148-153. doi:10.1080/02783190009554022

Guilford, J. P. (1950). Creativity. American Psychologist, 5 , 444-454.

Harris, A., \& Bruin, L. R. (2017). Secondary school creativity, teacher practice and STEAM education: An international study. Journal of Educational Change, 8(1), 1-27. doi:10.1007/s10833-017-9311-2

Hosseini, A. (2011). University student's evaluation of creative education in universities and their impact on their learning. Procedia Social and Behavioral Sciences, 15, 1806-1812. doi:10.1016/j.sbspro.2011.04.007

Kaufman, J. C., Beghetto, R. A., \& Pourjalali, S. (2011). Criatividade na sala de aula: uma perspectiva internacional. Em S. M. Wechsler \& V. L. T. Souza (Eds.), Criatividade e aprendizagem (pp. 53-72). São Paulo: Edições Loyola.

Libâneo, J. C., Oliveira, J. F., \& Toschi, M. S. (2005). Educação escolar: politicas, estrutura e organização (2 $2^{\mathrm{a}}$ ed). São Paulo: Cortez.

Lima, V. B. F., \& Alencar, E. M. L. S. (2014). Criatividade em programas de pós-graduação em educação: práticas pedagógicas e fatores inibidores. Revista Psico USF, 19(1), 61-72. doi:10.1590/ S1413-82712014000100007

Mariani, M. F. M., \& Alencar, E. M. L. S. (2005). Criatividade e trabalho pedagógico segundo Psico-USF, Bragança Paulista, v. 23, n. 3, p. 555-566, jul./set. 2018 
professores de História: limites e possibilidades. Psicologia Escolare Educacional, 9(1), 27-36. doi:10.1590/ S1413-85572005000100003

Martínez, A. M. (2006). Criatividade no trabalho pedagógico e criatividade na aprendizagem: uma relação necessária? Em M. C. V. R. Tacca (Eds.), Aprendizagem e trabalho pedagógico (pp. 69-94). Campinas: Alínea.

Ministério da Educação. (1997). Parâmetros curriculares nacionais $1^{a}$ a $4^{a}$ séries. Brasília: SEB/MEC.

Ministério da Educação. (1998). Parâmetros curriculares nacionais $5^{a}$ a $8^{a}$ séries. Brasília: SEB/MEC.

Ministério da Educação. (2010). Diretrizes curriculares para a educação infantil. Brasília: SEB/MEC.

Morgan, S., \& Foster, J. (1999). Creativity in the classroom. Gifted Education International, 14, 29-43. doi:10.1177/026142949901400105

Nakano, T. C. (2009). Investigando a criatividade junto a professores: pesquisas brasileiras. Psicologia Escolar e Educacional, 13(1), 45-53. doi:10.1590/ S1413-85572009000100006

Nakano, T. C., \& Wechsler, S. M. (2007). Criatividade: Características da produção científica brasileira. Avaliação Psicológica, 6(2), 261-270. Recuperado de: http://pepsic. bvsalud.org/scielo.php? script $=$ sci_arttext\&pid $=$ S1677-04712007000200015

Omdal, s. N., \& Graefe, A. K. (2017). Investing in creativity in students. Em J. A. Plucker (Ed.), Creativity \& innovation. Theory, research and practice (pp. 205222). Waco, TX: Prufrock Press.

Oliveira, E. B. P. \& Alencar, E. M. L. S. (2012). Importância da criatividade na escola e no trabalho docente segundo coordenadores pedagógicos. Estudos de Psicologia, 29(4), 541-552. doi:10.1590/ S0103-166X2012000400009
Oliveira, E. L. L., \& Alencar, E. M. L. S. (2010). Criatividade e escola: limites e possibilidades segundo gestores e orientadores educacionais. Psicologia Escolar e Educacional, 14(2), 245-260. doi:10.1590/ S1413-85572010000200007

Renzulli, J. S. (2016). Reexamining the role of gifted education and talent development for the $21^{\text {st }}$ century: A four-part theoretical approach. Em S. M. Reis (Ed.), Reflections on gifted education (pp. 31-51). Waco, TX; Prufrock Press.

Romo, M. (2012). Psicología da creatividad. Barcelona: Paidós.

Smith-Bingham, R. (2006). Public policy, innovation and the need for creativity. Em N. Jackson, M. Oliver, M. Shaw, \& J. Wisdom (Eds.), Developing creativity in bigher education (pp. 10-18). London: Routledge.

Souza, M. E., \& Alencar, E. M. L. S. (2006). O curso de pedagogia e as condições para o desenvolvimento da criatividade. Psicologia Escolar e Educacional, 10(1), 21-30. doi:10.1590/S1413-85572006000100003

Sternberg, R. J. (2015). Teaching for creativity: The sounds of silence. Psychology of Aesthetics, Creativity, and the Arts, 9(2), 115-117. doi:10.1037/aca0000007

Treffinger, D. J., Schoonover, P. F., \& Selby, E. C. (2013), Educating for creativity and innovation. Waco, TX: Prufrock Press.

Wechsler, S. M., \& Nakano, T. C. (2011). (Eds.). Criatividade no ensino superior: uma perspectiva internacional. São Paulo: Vetor.

Wechsler, S. M., \& Souza, V. L. T. (Eds.). (2011). Criatividade e aprendiragem. São Paulo: Edições Loyola.

Recebido em: 25/06/2017

Reformulado em: 28/02/2018

Aprovado em: 06/03/2018 
Sobre as autoras:

Eunice Soriano de Alencar é professora emérita do Instituto de Psicologia da Universidade de Brasília, cidadã honorária de Brasília, membro honorário do Conselho Brasileiro para Superdotação e autora de mais de 270 publicações, entre livros e artigos. Recebeu, ainda, numerosas honrarias, entre elas, a A. Harry Passow International Award for Leadership in Gifted Education, outorgado pelo World Council for Gifted and Talented Children.

E-mail: eunices.alencar@gmail.com

ORCID: 0000-0002-8220-6517

Denise de Souza Fleith é psicóloga pela Universidade de Brasília, Ph.D. em Psicologia Escolar pela University of Connecticut, professora titular do Instituto de Psicologia da Universidade de Brasília e pesquisadora do Conselho Nacional de Desenvolvimento Científico e Tecnológico. Integra, ainda, o comitê executivo do World Council for Gifted and Talented Children.

E-mail: fleith@unb.br

ORCID: 0000-0001-7512-8023

Clarissa Nogueira Borges é graduada em Psicologia pela Universidade Católica de Brasília, mestre em Processos de Desenvolvimento Humano e Saúde pela Universidade de Brasília e atua como psicóloga no atendimento educacional especializado ao estudante com altas habilidades/superdotação da Secretaria de Educação do Distrito Federal.

E-mail: claranogborges@hotmail.com

ORCID: 0000-0002-7287-663X

Evely Boruchovitch é psicóloga pela Universidade do Estado do Rio de Janeiro, Ph.D em Educação pela University of Southern California, Los Angeles, professora titular do Departamento de Psicologia Educacional da Faculdade de Educação da Universidade Estadual de Campinas-Unicamp, coordenadora da Linha Psicologia e Educação do Programa de Pós-graduação em Educação da Faculdade de Educação da Unicamp e bolsista de Produtividade do CNPq 1B.

E-mail: evely@unicamp.br

ORCID: 0000-0001-7597-6487

Contato com as autoras:

SHIS QL 10 conjunto 6, casa 14

Brasilia-DF, Brasil

CEP: 71630-065 